\title{
Topical retinoic acid changes the epidermal cell surface glycosylation pattern towards that of a mucosal epithelium
}

\author{
C.E.M.GRIFFITHS, E.DABELSTEEN* AND J.J.VOORHEES \\ Department of Dermatology, University of Michigan Medical Center, Ann Arbor, Michigan, U.S.A. \\ *School of Dentistry, Department of Oral Diagnostics, Copenhagen, Denmark
}

Accepted for publication 26 May 1995

Summary Topical all-trans retinoic acid (RA) produces a number of epidermal changes which are indistinguishable from those observed following treatment with a local irritant, namely sodium lauryl sulphate (SLS). This observation has led to criticism that the efficacy of RA in disorders such as photoageing, is merely a result of irritancy. In stratified epithelia, the cellular differentiation process is characterized by a stepwise synthesis of cell surface carbohydrates, and each type of stratified epithelium has its own specific pattern of carbohydrate expression. Glycosyltransferases, which are responsible for carbohydrate synthesis, are influenced by retinoids. Thus, we investigated whether epidermal cell surface glycosylation is altered in skin treated with topical RA, and contrasted it with changes induced by topical SLS.

Skin biopsies were obtained from seven normal volunteers who had been treated, on three separate areas of buttock skin, with single applications of $0 \cdot 1 \%$ RA, $2 \%$ SLS, or vehicle creams, followed by 4-day occlusion. Biopsies were assessed immunohistologically using highly specific monoclonal antibodies to cell surface carbohydrates (types 1,2 and 3 chain structures), previously demonstrated in the epidermis and in oral mucosal epithelium. Although type 1 chain structures were not demonstrated in any of the samples, the distribution of type 2 and 3 chain structures in RAtreated epidermis was altered towards that seen in a mucosal epithelium. T antigen, a mucin-type cell surface carbohydrate structure normally expressed throughout the epidermis, was only observed in the granular layer of RA-treated epidermis - a feature of mucosal epithelia. Le ${ }^{y}$, normally only seen in non-keratinized buccal epithelium, was strongly expressed in RA-treated epidermis. In contrast, the glycosylation pattern of the SLS-treated epidermis was not significantly different from that observed after vehicle treatment. Thus, RA treatment converts normal stratified epithelium towards the phenotype of mucosal epithelium with a decrease in T antigen and a concomitant increase in $\mathrm{Le}^{\mathrm{y}}$. These changes are not observed following treatment with SLS and identify an important difference between RA effects and irritancy.

Topical all-trans retinoic acid (RA) is efficacious for the treatment of various skin disorders, including acne ${ }^{1}$ and photoageing. $^{2}$ It is accepted that RA is beneficial in acne due to the normalization of follicular duct keratinocyte differentiation. However, the mechanism of action of RA in the improvement of clinical features of photoageing, namely wrinkling and actinic lentigines, is still controversial. This situation has arisen because the cutaneous erythema and scaling (retinoid dermatitis), associated with the use of topical RA. raises the possibility that RA is acting solely as a local irritant and that its actions are not an inherent property

Correspondence: Professor C.E.M.Griffiths, Section of Dermatology, University of Manchester School of Medicine. Hope Hospital, Salford M6 8HD, U.K. of the RA molecule. In addition, 4-day treatment of normal skin with RA, under occlusion, produces epidermal histological changes very similar to those produced by sodium lauryl sulphate (SLS) under the same conditions. ${ }^{3}$ However, RA produces changes not seen in SLS-treated skin, e.g. the induction of cellular retinoic acid binding protein $\Pi(\mathrm{CRABP}-\Pi)^{4}$ and the induction of RA 4-hydroxylase activity, ${ }^{5}$ both of which are important in RA metabolism.

At the cell surface, monosaccharides are linked together in different sequences by different glycosidic linkages, thereby generating a vast number of complex saccharide chains ${ }^{6,7}$ (Fig. 1). In the stratified epithelia of skin and oral mucosa, the cellular differentiation process is characterized by a stepwise synthesis of cell 

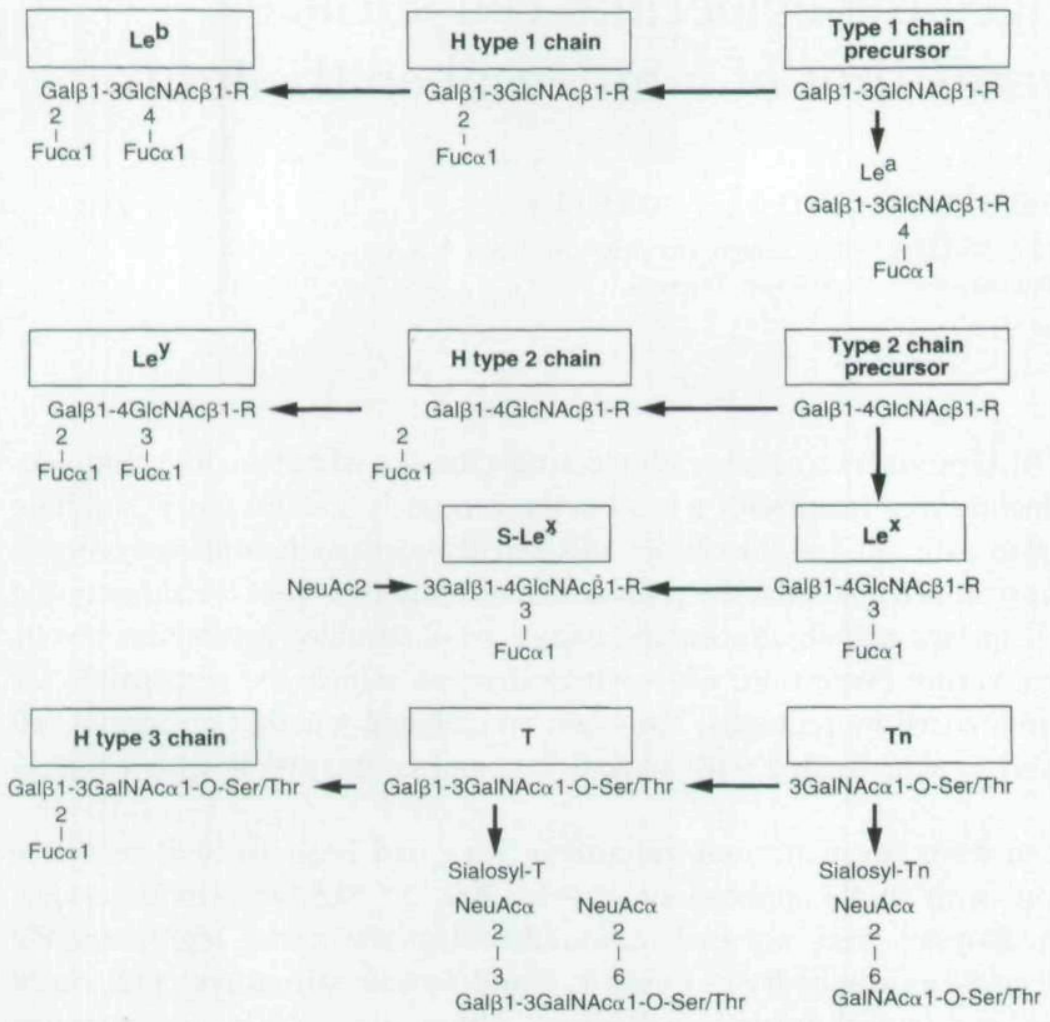

Figure 1. Biosynthetic pathway for types 1,2 , and 3 chain carbohydrate antigens. Arrows indicate the synthetic sequence of these structures. Types 1 and 2 chain precursors may be carried either on glycoproteins or glycolipids, whereas type 3 chain structures are $\mathrm{O}$-linked carbohydrate chains bound to serine or threonine. Each biosynthetic step is catalysed by a specific enzyme; type 1 chain structures are found exclusively in mucosal epithelium, whereas type 2 and 3 chains may be found in mucosal as well as epidermal cells. surface carbohydrates. ${ }^{8,9}$ The different types of stratified epithelium have their own specific pattern of carbohydrate expression, which may vary in relationship to certain physiological and pathological conditions. ${ }^{10-14}$

It appears that RA-treated epidermis takes on some of the characteristics of mucosal epithelia, i.e. glycosaminoglycan accumulation ${ }^{1,15}$ and the expression of keratin $13 .{ }^{16}$ Expression of glycosyltransferases, which are responsible for the synthesis of cell surface carbohydrate chains, is changed in vitro by $\mathrm{RA},{ }^{17}$ indicating that RA may ultimately regulate the expression of cell surface carbohydrates. In the light of these observations, and in an attempt to further characterize the differences between RA and SLS-treated skin, we examined the ability of these two compounds to modulate the expression of epidermal cell surface carbohydrates, i.e. the glycosylation pattern.

\section{Materials and methods}

\section{Patients}

Seven normal volunteers (age range 35-45 years) were treated on three separate areas of the hips or buttocks with single applications of $0 \cdot 1 \%$ RA cream (Retin-A-, Ortho Pharmaceutical Corp., Raritan, NJ, U.S.A.) colour-matched, vehicle cream (Ortho), or 2\% SLS (Duponol-C, Dupont Co., Wilmington, DE, U.S.A.) formulated in Retin-A vehicle cream. The treated areas were occluded with light-tight plastic for 4 days. We have previously demonstrated that $0 \cdot 1 \%$ RA and $2 \%$ SLS creams produce almost identical erythema and epidermal histological changes under these treatment conditions. ${ }^{3}$ At 4 days, the occlusion was removed and 4-mm punch biopsies taken from all treatment sites under $1 \%$ lignocaine anaesthesia. The biopsies were snap frozen in liquid nitrogen and stored at $-70^{\circ} \mathrm{C}$ until use.

All volunteers gave written consent and the protocol was approved by the University of Michigan Medical Center Institutional Review Board.

\section{Immunochemistry}

Five-micrometer cryostat sections were air-dried and stained using a double-layer technique ${ }^{10}$ with wellcharacterized monoclonal antibodies to carbohydrate epitopes (Table 1). ${ }^{18-23}$ In brief, frozen sections were air-dried and incubated in a moist chamber with a monoclonal antibody for $18 \mathrm{~h}$ at $4^{\circ} \mathrm{C}$. Following three washes in phosphate-buffered saline (PBS) $\mathrm{pH} 7 \cdot 2$ $(5 \mathrm{~min}$ each), fluorescein isothiocyanate (FITC)conjugated rabbit anti-mouse immunoglobulin, diluted 
Table 1. Panel of mouse monoclonal antibodies used

\begin{tabular}{lcc}
\hline Antibody/isotype & Antigen & Source (reference) \\
\hline CF4-C/IgG & $\mathrm{Le}^{\mathrm{a}}$ & $(18)$ \\
Anti-Le $/ \mathrm{IgM}$ & $\mathrm{Le}^{\mathrm{b}}$ & Chembiomed, Canada \\
$1 \mathrm{~B} 2 / \mathrm{IgM}$ & $\mathrm{N}-\mathrm{Lac}^{\mathrm{H}}$ & $(19)$ \\
$\mathrm{BE} 2 / \mathrm{IgM}$ & $\mathrm{H}$ & $(19)$ \\
$\mathrm{SH} 1 / \mathrm{IgG}$ & & $(20)$ \\
$\mathrm{AH} 6 / \mathrm{IgM}$ & $\mathrm{Le}^{x}$ & $(21)$ \\
$\mathrm{FH} 6 / \mathrm{IgM}$ & $\mathrm{Le}^{y}$ & $(22)$ \\
$\mathrm{HB}-\mathrm{Tn} / \mathrm{IgM}$ & $\mathrm{MsLe}^{x}$ ext. & DAKO, Denmark \\
$\mathrm{HB}-\mathrm{T} / \mathrm{IgM}$ & $\mathrm{Tn}$ & DAKO, Denmark \\
$\mathrm{HH} 14 / \mathrm{IgM}$ & $\mathrm{T}$ & $(23)$ \\
& $\mathrm{H}$ & \\
\hline
\end{tabular}

1:40 (Dakopatts, Copenhagen, Denmark), was applied for $40 \mathrm{~min}$. The sections were again washed and mounted in PBS containing $p$-phenylene-diamine in glycerol. All monoclonal antibodies were from hybridoma culture supernatants containing approximately $10-30 \mu \mathrm{g}$ of immunoglobulin per millilitre. In order to unmask antigenic determinants, enzymatic deglycosylation of sialic acid residues was performed by neuraminidase treatment of additional sections before staining, as described previously. ${ }^{10}$ In brief, sections were incubated with neuraminidase type 6 (Sigma Chemical Co, St Louis, MO, U.S.A.) from Clostridium perfringens type 6 (Sigma), 0.1 U of neuraminidase per millilitre in a $0.1 \mathrm{~mol} / \mathrm{l}$ acetate, and $0.04 \mathrm{~mol} / 1 \mathrm{CaCl}_{2}$ buffer at $\mathrm{pH} 5 \cdot 5$. The slides were examined, under epiillumination, using a Zeiss fluorescence microscope equipped with a FITC interference filter and a 50-W xenon lamp. Control reactions for the specificity of the staining consisted of: (i) staining with conjugate alone; (ii) substitution of the primary monoclonal antibody with monoclonal antibodies of irrelevant specificity but of the same isotype; and (iii) substitution of the primary antibody with culture supernatant from the myeloma line $(\mathrm{Sp} 2 / 0)$ used for hybridization, so as to control for the culture medium and nonspecific secretions from the myeloma cell line.

\section{Quantification of staining}

Epidermal thickness was graded from 2 (normal thickness) to a maximum of 6 . Epidermal $\mathrm{T}$ antigen expression was graded on a $0-3$ scale where 0 is staining of $0-1$ cell layers; $1,2-4$ layers; $2,>4$ but not all cell layers; and 3, staining of entire epidermis. Epidermal $\mathrm{Le}^{\mathrm{y}}$ expression was also graded on a $0-3$ scale, where 0 is no staining: 1,1 superficial cell layer (granular layer); 2, 2-3 superficial cell layers (granular and upper spinous); and 3, >3 cell layers stained.

\section{Statistical methods}

The sign test was used to compare the presence or absence of staining among treatments for $\mathrm{T}$ antigen as well as Le ${ }^{y}$. The Friedman rank sum and multiple comparison tests were used to compare group differences in epithelial thickness. All $P$-values are two-sided. Summary statistics are expressed as means \pm standard error of the mean (SEM). The data were analysed with the Michigan Interactive data analysis system, a statistical software package developed by the Center for Statistical Consultation and Research at the University of Michigan.

\section{Results}

As previously observed, ${ }^{3}$ both RA and SLS treatments thickened the epidermis. However, there was no significant difference between the epidermal thickness of RA and SLS-treated skin (Table 2).

Type 1 chain structures $\left(\mathrm{Le}^{\mathrm{a}}\right.$ and $\left.\mathrm{Le}^{\mathrm{b}}\right)$ could not be demonstrated in vehicle-, SLS- or RA-treated skin. $\mathrm{H}$ antigen, which is a precursor of $\mathrm{Le}^{y}$, was not seen in RA-treated tissue but was present in the granular cell layer of vehicle- and SLS-treated skin, whereas $\mathrm{N}$-acetyllactosamine, the precursor of $\mathrm{H}$ antigen, was weakly expressed in all samples. Pretreatment with neuraminidase showed strong staining in the spinous cell layer, indicating that most of the $\mathrm{N}$-acetyllactosamine is masked by sialic acid. We could not demonstrate $\mathrm{Le}^{\mathrm{x}}$ in any biopsies. However, sialylated $\mathrm{Le}^{\mathrm{x}}$ was seen in all biopsies, as cell surface staining on epidermal dendritic cells, most probably Langerhans cells, as has been

Table 2. Effects of 4-day treatment with $0 \cdot 1 \%$ retinoic acid (RA), $2 \%$ sodium lauryl sulphate (SLS) or vehicle creams on epidermal thickness, $\mathrm{Le}^{\mathrm{y}}$ and $\mathrm{T}$ antigen expression in normal skin

\begin{tabular}{|c|c|c|c|}
\hline Histological parameter & $\begin{array}{l}\text { Vehicle } \\
(n=6)\end{array}$ & $\begin{array}{c}0 \cdot 1 \% \text { RA } \\
(n=7)\end{array}$ & $\begin{array}{l}2 \% \text { SLS } \\
(n=7)\end{array}$ \\
\hline Epidermal thickness & $2 \cdot 0 \pm 0^{\mathrm{a}}$ & $3 \cdot 3 \pm 0 \cdot 5^{b}$ & $2 \cdot 6 \pm 0 \cdot 2^{h}$ \\
\hline $\mathrm{T}$ antigen & $3 \cdot 0 \pm 0^{\mathrm{a}}$ & $0 \cdot 71 \pm 0 \cdot 3^{b}$ & $3 \cdot 0 \pm 0^{\mathrm{a}}$ \\
\hline $\mathrm{Le}^{y}$ & $0 \pm 0^{a}$ & $2 \cdot 0 \pm 0 \cdot 4^{b}$ & $0 \pm 0^{\mathrm{a}}$ \\
\hline
\end{tabular}

For scales used to estimate epidermal thickness, T antigen and $\mathrm{Le}^{\mathrm{y}}$ expression see text. All values are mean \pm standard error of mean (SEM).

${ }^{a, b}$ For each parameter, pairwise comparison of means with at least one superscript in common denotes non-significant differences at the $0 \cdot 05$ level. 
described previously. ${ }^{24,25} \mathrm{Le}^{\mathrm{y}}$, a type 2 chain structure, was not observed in either vehicle- or SLS-treated skin, but was strongly expressed as keratinocyte cell surface staining in the upper epidermis of RA-treated skin (Table 2; Fig. 2). T antigen, a type 3 chain structure, was expressed throughout the epidermis in vehicle- and SLS-treated skin but was only observed in the granular layer of RA-treated epidermis $(P=0 \cdot 03$, Table 2, Fig. 2).

All other carbohydrate structures investigated showed no differences between RA-, SLS- and vehicle-treated skin, and were distributed as described previously. ${ }^{9,10}$

\section{Discussion}

Cell surface carbohydrates are of considerable interest in studies of epithelial cells because these structures vary markedly with important cellular processes such as development, differentiation, and oncogenic transformation. ${ }^{8-14}$ In stratified epithelium, basal cells express short and unbranched carbohydrates whereas suprabasal layers express carbohydrates with longer structures. ${ }^{8}$ Changes in expression of cell surface carbohydrates may be due to changes in glycosyltransferase activity or to competition between different glycosyltransferases for a common substrate. ${ }^{6,7}$ As terminal portions of carbohydrates are strongly immunogenic, it is possible to raise antibodies useful for their identification. ${ }^{26}$ Different carbohydrate terminal structures are termed types $1,2,3$ and $4,{ }^{27}$ and these structures have different tissue distributions. Types 1,2 , and 3 are found in non-keratinized (mucosal) epithelium, ${ }^{28}$ whereas only types 2 and 3 are found in keratinized epithelium. ${ }^{8,14}$ Previous work $^{16}$ has shown a mucosal-like expression of keratin, involucrin and epidermal transglutaminase in RA-treated skin, i.e. expression of keratin 13 and precocious suprabasal expression of involucrin and epidermal transglutaminase. Thus, our current study supports the concept of RA-treated skin assuming the phenotype of a mucosal epithelium.

We studied three groups of carbohydrate structures with well-known biosynthetic precursor product relationships, including types 1,2 and mucin-type 3
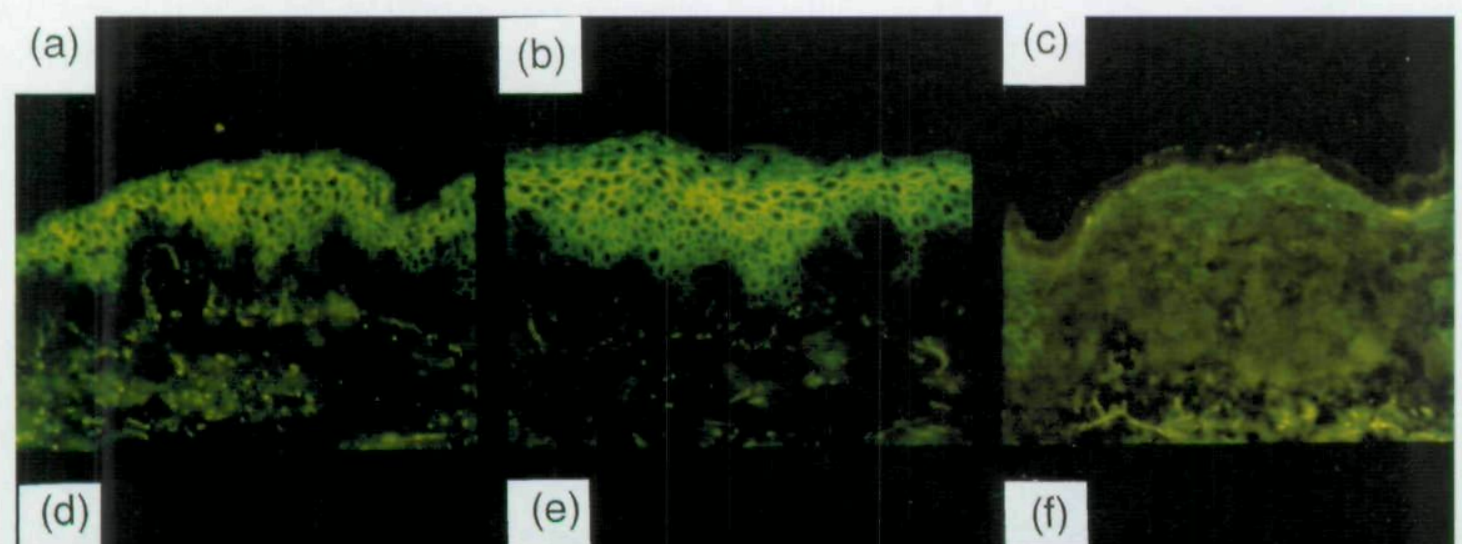

(f)
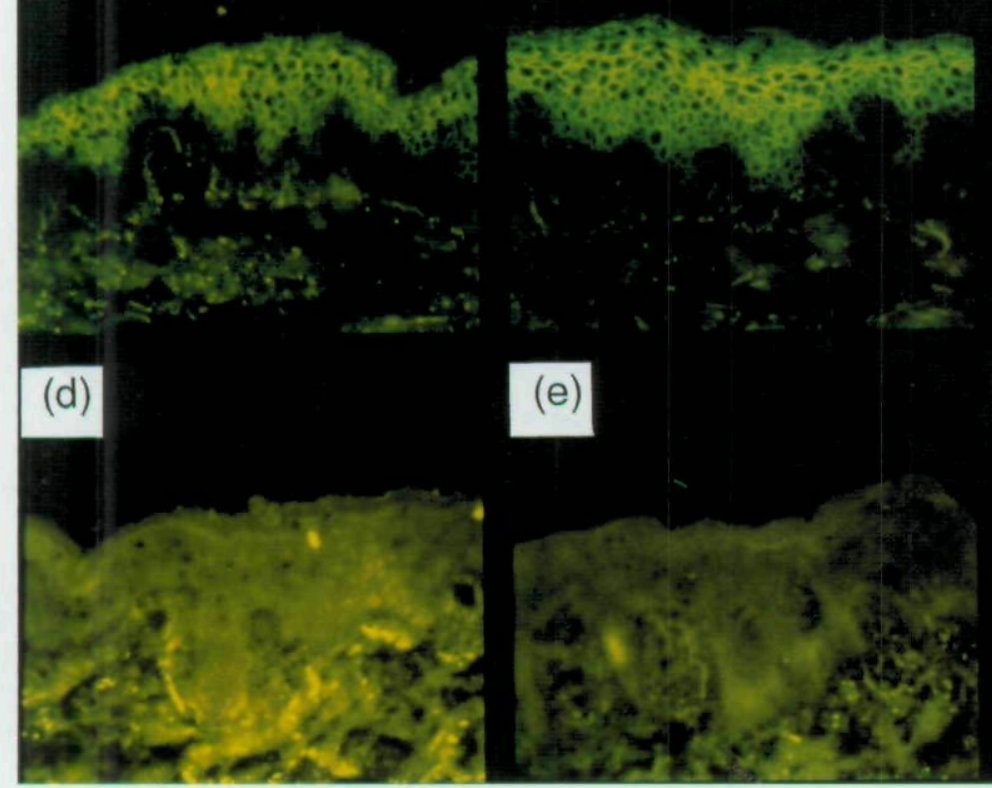

e)

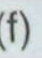

Figure 2. Retinoic acid (RA) alters expression of cell surface carbohydrates in human epidermis. Vehicle, $2 \%$ sodium lauryl sulphate (SLS) and $0 \cdot 1 \%$ RA creams were applied topically to normal skin and occluded for 4 days. Sections from vehicle (a and d), SLS (b and e) and RA (c and f) treated skin were stained with an immunofluorescence method to detect cell surface carbohydrates. (a-c) represent sections stained with antibody to T antigen, whereas $(\mathrm{d}-\mathrm{f})$ represent sections stained with antibody to $\mathrm{Le}^{\mathrm{y}}$. Positive epidermal keratinocyte cell surface staining is identifiable as green 'chickenwire', whereas non-specific, background staining, is yellow. In RA-treated epidermis, T antigen is only present on the most superficial cells in the spinous cell layer (c), whereas in vehicle (a) and SLS-treated epidermis (b) T antigen is present on all spinous cells. Le ${ }^{y}$ is only expressed in RA-treated epidermis (f) and is not expressed in either vehicle (d) or SLS-treated epidermis (e) $(\times 50)$. 
chain, in skin treated with either RA, SLS or a nonirritant vehicle. We found that distribution of carbohydrate structures in SLS and vehicle-treated epidermis corresponds to that seen in the normal epidermis. Type 1 chain structures that are normally expressed only in mucosal epithelium ${ }^{8,14}$ were not found in any of the skin samples. However, type 2 and 3 chains showed some mucosa-like expression in RA-treated skin. In normal stratified epithelium there is a sequential expression of type 2 chain $\mathrm{N}$-acetyllactosamine, $\mathrm{H}$ antigen and blood group A and B antigens in A- and B-positive individuals. $^{9,10}$ However, in RA-treated skin, the epidermis expressed Le ${ }^{y}$ (Fig. 2), which is a fucosylsubstituted version of the $\mathrm{H}$ antigen not present in normal epidermis but strongly expressed in mucosal epithelium. ${ }^{10,29} \mathrm{H}$ antigen, which is found in normal epidermis, could not be detected in RA-treated epidermis. Activity of the enzymes required for synthesis of $\mathrm{H}$ antigen and $\mathrm{Le}^{\mathrm{y}}$ has previously been demonstrated in normal epithelium. ${ }^{9,10}$ However, these activities have been expressed in different cell layers and, therefore, did not result in expression of $\mathrm{Le}^{\mathrm{y}}$ but in two precursor structures, ${ }^{11}$ namely Le ${ }^{x}$ and $\mathrm{H}$ (Fig. 2). The present work demonstrates that RA-treated skin has an alteration in the differentiation pattern, thereby leading to expression of $\mathrm{X}$ and $\mathrm{H}$ enzymes in the same cells, and leading to a new cell surface carbohydrate structure, i.e. $\mathrm{Le}^{\mathrm{y}}$.

$\mathrm{T}$ antigen is an $\mathrm{O}$-linked, mucin-like, carbohydrate structure. ${ }^{30,31}$ In the normal epidermis, $T$ antigen is found on spinous and, to some extent, basal cells, ${ }^{9}$ but following RA treatment, it could only be demonstrated in the granular cell layer. Attempts to demonstrate the precursor structures of T antigen (Tn and sialosyl-Tn) in the basal and spinous cell layers failed. We believe that $\mathrm{T}$ antigen in basal and spinous cell layers in RA-treated tissue is masked by branching and elongation of carbohydrate structures, thereby leading to a mucin-type glycosylation, ${ }^{27}$ an observation which would be in agreement with other studies indicating a mucous type of differentiation after retinoid treatment. ${ }^{1,15}$ This hypothesis is supported by studies of the effects of RA on a mouse teratocarcinoma cell line, F9. ${ }^{17}$ Such studies have shown that RA treatment induces differentiation of F9 cells into primitive endoderm-like cells, associated with upregulation of $\mathrm{N}$-acetylglucosamine-transferases which are responsible for synthesis of cell surface $\mathrm{O}$-linked polylactosamine. A polylactosamine elongation of $\mathrm{T}$ antigen will block tissue staining with anti-T antibodies, and could lead to some of the changes in cell surface carbohydrates observed in RA-treated skin. The effect of retinoids on expression of other glycosyltransferases is at present unknown.

In summary, we demonstrate that the glycosylation pattern of SLS-treated epidermis is not significantly different from that seen in normal skin and that RAtreated epidermis strongly expresses $\mathrm{Le}^{\mathrm{y}}$ and minimally expresses $\mathrm{T}$ antigen-features of mucosal epithelia. These observations are compatible with the idea that topical RA and irritants have differing effects on the epidermis.

\section{Acknowledgments}

This work was supported in part by the R.W.Johnson Pharmaceutical Research Institute, Raritan, NJ, U.S.A., the Babcock Dermatologic Endowment Fund, Ann Arbor, MI, U.S.A., and the Meta and Håkon Baggers Foundation, Denmark. We are grateful to $\mathrm{Mr}$ Ted A.Hamilton for statistical analysis.

\section{References}

1 Kligman AM, Futton JE. Plewig G. Topical vitamin A acid in acne vulgaris. Arch Dermatol 1969; 99: 469-76.

2 Weiss JS, Ellis CN, Headington JT et al. Topical tretinoin improves photoaged skin: a double-blind vehicle controlled study. JAMA 1988: 259: 527-32.

3 Fisher GJ, Esman J, Griffiths CEM et al. Cellular, immunologic and biochemical characterization of topical retinoic acid-treated human skin. J Invest Dermatol 1991; 96: 699-707.

4 Elder JT, Cromie MA, Griffiths CEM et al. Stimulus selective induction of CRABP-II mRNA: a marker for retinoic acid action in human skin. J Invest Dermatol 1993; 100: 356-9.

5 Duell EA. Astrom A. Kang S et al. All-trans, 9-cis and 13-cis retinoic acid each induce a cytochrome $\mathrm{P} 450$ retinoic acid 4-hydroxylase which causes all-trans but not 9-cis retinoic acid to self metabolise. J Invest Dermatol 1994; 102: 641A.

6 Samuelsson BE. Breimer ME. ABH antigens: some basic aspects. Transplant Proc 1987: 19: 4401-7.

7 Kleene R, Berger EG. The molecular and cell biology of glycosyltransferases. Biochem Biophys Acta 1993; 1154: 283-325.

8 Dabelsteen E, Mandel U, Clausen H. Cell surface carbohydrates are markers of differentiation in human oral epithelium. CRC Crit Rev Oral Biol Med 1991: 2: 493-507.

9 Dabelsteen E. Buschard K. Hakomori S. Young WWJr. Pattern of distribution of blood group antigens on human epidermal cells during maturation. I Invest Dermatol 1984; 82: 13-17.

10 Dabelsteen E. Broby-Johansen U, Jeppe-Jensen D, Mandel U. Cell surface glycosylation patterns in psoriasis. APMIS 1990: 98: 221-8.

11 Dabelsteen E. Clausen H. Mandel U. Carbohydrate changes in squamous cell carcinomas. APMIS 1992; 100 (Suppl. 27): 1308.

12 Fenderson BA, Eddy EM, Hakomori S. The blood group I antigen defined by monoclonal antibody C6 is a marker of early mesoderm during murine embryogenesis. Differentiation 1988: 38: 124-33.

13 Hakomori S, Aberrant glycosylation in tumors and tumorassociated carbohydrate antigens. Adv Cancer Res 1989; 52; 257-331. 
14 Oriol R. Genetic control of the fucosylation of ABH precursor chains. Evidence for new epistatic interactions in different cells and tissues. J Immunogenet 1990; 17: 235-45.

15 Fisher GJ. Tavakkol A, Griffiths CEM et al. Differential modulation of transforming growth factor- $\beta_{1}$ expression and mucin deposition by retinoic acid and sodium lauryl sulfate in human skin. J Invest Dermatol 1991; 98: 102-8.

16 Rosenthal DS, Griffiths CEM, Yuspa SH et al. Acute or chronic topical retinoic acid treatment of human skin in vivo alters the expression of epidermal transglutaminase, loricrin, involucrin. filaggrin and keratins 6 and 13 but not keratins 1, 10 and 14. J Invest Dermatol 1992; 98: 343-50.

17 Heffernan M, Lotan R. Amos B et al. Branching $\beta 1-6 \mathrm{~N}-$ acetylglucosaminetransferases and polylactosamine expression in mouse F9 teratocarcinoma cells and differentiated counterparts. J Biol Chem 1993: 268: 1242-51.

18 Young WW. Johnson HS. Tamura Y et al. Characterization of monoclonal antibodies specific for Lewis a human blood group determinant. J Biol Chem 1983; 258: 4890-4.

19 Young WW, Portoukalian J, Hakomori S. Two monoclonal anticarbohydrate antibodies directed to glycosphingolipids with a lacto-N-glycosyl type II chain. I Biol Chem 1982; 256: $10967-72$.

20 Fukushi Y, Hakomori S, Nudelman E, Cochan N. Novel fucolipids accumulating in human adenocarcinoma. II Selective isolation of hybridoma antibodies that differentially recognize mono-di- and trifucosylated type 2 chain. J Biol Chem 1984; 259: 4681-5.

21 Abe K, McKibbin JM. Hakomori S. The monoclonal antibody directed to difucosylated type 2 chain Fuc-alpha-1-2-Gal-beta-14(Fuc-alpha-1-3-Glc-NAc) Y determinant. J Biol Chem 1983; 258: 11793-7.
22 Fukushi Y, Nudelman E, Levery SB et al. Novel fucolipids accumulating in human adenocarcinoma. III A hybridoma antibody (FH6) defining a human cancer-associated difucoganglioside (VI3-NeuAcV-3III3-Fuc2-n1-c6). J Biol Chem 1984: 259: 10511-17.

23 Clausen H, Levery SB, Kannagi R, Hakomori S. Novel blood group $\mathrm{H}$ glycolipid antigens exclusively expressed in blood group $\mathrm{A}$ and $\mathrm{AB}$ erythrocytes (type 3 chain $\mathrm{H}$ ). I. Isolation and chemical characterization. J Biol Chem 1986: 261: 1380-7.

24 Nylander K. Larsen JK. Larsen J et al. The EL.AM-1 ligand sialosyl$\mathrm{Le}^{\mathrm{x}}$ is present on Langerhans cells isolated from stratified epithelium. Exp Dermatol 1992: 1: 236-41.

25 Tabata N. Aiba S, Nakagawa S et al. Sialyl Lewis ${ }^{x}$ expression on human Langerhans cells. J Invest Dermatol 1993; 101: 175-9.

26 Hakomori S. Monoclonal antibodies directed to cell-surface carbohydates. In: Monoclonal Antibodies and Functional Cell Lines, Progress and Applications (Kennett RH, ed.), New York: Plenum Press, 1984: 67-100.

27 Clausen H, Hakomori S. ABH and related histo-blood group antigens; immunochemical differences in carrier isotypes and their distribution. Vox Sang 1989: 56: 1-20.

28 Reibel J. Clausen H. Dale BA. Thacher S. Immunohistochemical analysis of stratum corneum components in oral squamous epithelia. Differentiation 1989; 41: 237-44.

29 Mandel U, Orntoft T, Holmes EH et al. Lewis blood group antigens in salivary glands and stratified epithelium: lack of regulation of Lewis antigen expression in ductal and buccal mucosal lining epithelia. Vox Sang 1991; 61: 205-14.

30 Carraway KI, Hull SR. Cell surface mucin-type glycoproteins and mucin-like domains. Glycobiol 1991: 1: 131-8.

31 Mandel U, Petersen OW. Sorensen H et al. Simple mucin-type carbohydrates in oral stratified squamous and salivary gland epithelia. J Invest Dermatol 1991; 97: 713-21. 
This document is a scanned copy of a printed document. No warranty is given about the accuracy of the copy. Users should refer to the original published version of the material. 